\title{
Horizontal Product Differentiation in Auctions and Multilateral Negotiations*
}

\author{
Charles J. Thomas \\ John E. Walker Department of Economics \\ Clemson University \\ 222 Sirrine Hall \\ Clemson, SC 29634 \\ E-mail:cjt@clemson.edu
}

\author{
Bart J. Wilson \\ Economic Science Institute \\ Chapman University \\ One University Drive \\ Orange, CA 92866 \\ E-mail:bartwilson@gmail.com
}

August, 2011

Abstract: We experimentally compare first-price auctions and multilateral negotiations after introducing horizontal product differentiation into a standard procurement setting. Both institutions yield identical surplus for the buyer, a difference from prior findings with homogeneous products that results from differentiation's influence on sellers' pricing behavior. The data are consistent with this finding being driven by concessions from low-cost sellers in response to differentiation reducing their likelihood of being the buyer's surplus-maximizing trading partner. Further analysis shows that introducing product differentiation increases or leaves unchanged the intensity of price competition among sellers, which contrasts with the conventional wisdom that product differentiation softens competition.

\footnotetext{
${ }^{*}$ We thank the International Foundation for Research in Experimental Economics for providing financial support, and Jeffrey Kirchner for writing the software. The data and instructions are available upon request. Ovidiu Lasca, Mike Maloney, Curtis Simon, Angie Starrett, Patrick Warren, and seminar participants at Clemson University and the University of South Carolina provided helpful comments and advice.
}

JEL: C78, D44, C9, L14

Keywords: voluntary exchange, multilateral negotiations, auctions, product differentiation 


\section{Introduction}

Understanding the variety of ways in which voluntary exchange is conducted is a fundamental goal of economics, in part to enable an informed choice amongst exchange methods by using metrics such as profitability or efficiency. For example, in different settings bargaining, auctions, and posted prices all are used to arrange for the trade of goods and services. Variants emerge that blur the lines between what previously appeared to be distinct types of exchange methods. ${ }^{1}$ In fact, some of these new methods themselves become "goods and services," with their designers applying for patent protection and being hired to organize markets. ${ }^{2}$

Previous research suggests that a trading mechanism's performance depends on characteristics of the strategic environment in which it is used. For example, Klemperer [2002] argues that one size does not fit all in auction design, with factors such as the number of potential bidders, their relative size or importance, and the likelihood of collusion meriting careful consideration. Similarly, theoretical arguments show that it matters who makes offers in bilateral bargaining when there is one-sided private information. ${ }^{3}$

With the preceding points in mind, in this paper we use the experimental method to evaluate how introducing horizontal product differentiation into a standard procurement setting affects the outcomes of two commonly used means of exchange, auctions and multilateral negotiations. Auctions are used in procurement and to allocate products such as electric power, pollution rights, art, and government securities. ${ }^{4}$ Multilateral negotiations combine features of auctions and bilateral bargaining, although they have received much less academic attention than

\footnotetext{
${ }^{1}$ Consider the "Anglo-Dutch" auction described in Klemperer [2002], the simultaneous ascending auction, used to sell U.S. radio spectrum, described in Milgrom [2000], or the "Buy It Now” feature in auctions on E-Bay.

${ }^{2}$ Companies such as MercExchange, Inc. and Ozro, Inc. have obtained patents covering online auctions and electronic negotiations, respectively. Economists such as Paul Milgrom and Larry Ausubel also hold patents on different auction designs.

${ }^{3}$ Kennan and Wilson [1993] provide an excellent overview of bargaining with private information.

${ }^{4}$ See Wolfram [1998], Cason [1995], Milgrom and Weber [1982], and McAfee and McMillan [1987].
} 
have those two exchange methods. ${ }^{5}$ In them, a buyer solicits offers from multiple sellers, and then plays the sellers off one another to receive additional concessions. They are used in settings such as procurement, high-end job markets, and the purchase of contractors' services and automobiles. Given that auctions and multilateral negotiations often are used in similar settings, even by apparently similar buyers in narrowly defined markets, our primary reason for investigating them is to see if they yield equivalent outcomes.

One reason we consider product differentiation is that analyses of auctions and multilateral negotiations typically assume that bidders are homogeneous from the auctioneer's perspective, ${ }^{6}$ but frequently in procurement the buyer has preferences over non-price attributes of the sellers' products. For example, when Airbus and Boeing competed for a sizeable contract from Iberia Airlines in 2003, both sellers had to deal with Iberia’s privately known preferences. ${ }^{7}$ These stemmed from Iberia's evaluation of differences in the sellers' product characteristics, and of how its fleet composition would affect maintenance costs and future procurement episodes. Similar stories abound from companies like Hewlett-Packard, IBM, Kaiser Permanente, Nissan, Pfizer, and Sun Microsystems. ${ }^{8}$ Product differentiation's prevalence in procurement makes investigating its effect on behavior worthwhile.

A second reason we consider product differentiation is that prior research finds that some auction formats give the buyer more surplus than do multilateral negotiations, which leaves open the question of why multilateral negotiations are so commonly used. One reason may be that

\footnotetext{
${ }^{5}$ See Thomas and Wilson [2002, 2005], along with related work in Cason, et al [2003].

${ }^{6}$ For example, see Milgrom and Weber [1982], McAfee and McMillan [1987], Wolfram [1998], Waehrer and Perry [2003], and Thomas and Wilson [2002, 2005].

7 “Airbus and Boeing Duke it Out to Win Lucrative Iberia Deal,” Wall Street Journal, March 10, 2003.

${ }^{8}$ See the following articles in Purchasing, or at purchasing.com: "HP's Purchasing Organization Looks Beyond Price,” September 11, 2008; “It’s Not Just About Cost,” March 15, 2007; "Procurement Brings Green Initiatives to Life at Kaiser Permanente,” December 13, 2007; “Nissan Pushes Suppliers on Quality,” October 5, 2006; "Pfizer’s Procurement Provides 12 Tips for Reverse Auction Success,” December 11, 2008; “Sun’s e-Auction Evolution,” September 13, 2007.
} 
real strategic environments differ in important dimensions from the settings that so far have been examined. Differentiation may be one such dimension, and when it is present we hypothesize that the dynamic nature of multilateral negotiations allows the buyer to profitably exploit its privately known preferences in a way that one-shot auctions do not. If so, then in this setting the buyer may receive relatively more surplus by using negotiations than by using auctions.

We introduce horizontal product differentiation by using a linear random utility model that we modify so each seller's production cost is its private information. ${ }^{9}$ Private information about the buyer's values and the sellers' costs contributes to the main difference between the auctions and the negotiations, namely that the communication allowed by the negotiations provides opportunities for each party to signal or misrepresent its private information in an attempt to secure more of the gains from trade. ${ }^{10}$

We use experiments to evaluate the effect of product differentiation on auctions and multilateral negotiations because theoretical characterization of equilibrium behavior in the setting we consider remains an open problem. Our approach accords with the theoretical perspective of Muthoo [1999, p.342] that a "primary role of bargaining experiments should be to make new discoveries about bargaining - for example, to identify new forces that may have a significant impact on the bargaining outcome. In that way bargaining experiments can help in the further development of the theory of bargaining." Muthoo's insights complement the experimental perspective articulated by Smith [1982]. He advocates heuristic investigations of new environments and institutions, especially when strategic complexity leads to analytic intractability, because "it is through exploratory probes of new phenomena that attention may be redirected, old belief systems may be reexamined, and new scientific questions may be asked”

\footnotetext{
${ }^{9}$ See Anderson, de Palma, and Thisse [1992] for a comprehensive treatment of discrete choice models.

${ }^{10}$ Similar incentives exist in bilateral bargaining with private information. See Fudenberg and Tirole [1983] for an early treatment.
} 
(p. 942). In this vein, economic experiments have recently played a major role in test-bedding spectrum auctions, wholesale markets for electric power, and NOx allowance auctions. ${ }^{11}$

Introducing product differentiation yields several questions of interest. First, how do the outcomes of auctions and multilateral negotiations compare when there is product differentiation? We find that both institutions yield the buyer the same expected surplus, which helps explain the prevalence of multilateral negotiations despite earlier results suggesting that buyers might prefer auctions. With homogeneous products Thomas and Wilson [2002] find that auctions yield higher surplus than do multilateral negotiations with two sellers, but yield the same surplus with four sellers. The present findings suggest that having privately known preferences over the sellers' products allows the buyer to extract relatively more surplus from the sellers when negotiating than when using an auction, at least when there are few sellers.

Second, can we determine how these changes in the institutions' relative performance occur? That is, from the buyer's perspective, does introducing product differentiation improve the negotiations' performance, degrade the auctions' performance, or lead to some other change? To address this issue we measure the intensity of competition among the sellers, and we find a surprising result. With two sellers following the introduction of product differentiation, price competition in both institutions intensifies to different extents. This finding suggests that the buyer benefits from having privately known preferences, and this benefit is greater in the negotiations. With four sellers there is no discernible change in the intensity of price competition in either institution. While the latter finding's difference from the former simply may reflect that the settings with four sellers are intensely competitive regardless of product

\footnotetext{
${ }^{11}$ See Banks, et al [2003], Rassenti, Smith, and Wilson [2002], and Porter, et al [2009].
} 
characteristics, both findings contrast with the conventional wisdom that product differentiation softens competition among sellers. ${ }^{12}$

The rest of the paper is organized as follows. Section 2 describes the theoretical framework underlying our strategic setting, while Section 3 describes related research. Sections 4 and 5 present our experimental design and findings, while Section 6 briefly concludes.

\section{Modeling Framework}

In this section we present a model of the strategic environment in which auctions and multilateral negotiations are used. It is identical to the model in Thomas and Wilson [2002, 2005], but for the addition of the buyer's privately known preferences for the sellers' products. The model illustrates details underlying our experimental design and provides guidance for future theoretical analyses. We conclude by describing our conjectures about the effects of introducing product differentiation in multilateral negotiations and auctions.

Building upon the modeling framework used in earlier analyses allows us to compare our new results with prior observations. This comparison lets us clearly see the effect of introducing privately known preferences for the buyer, using as a starting point an established set of results involving homogeneous products. ${ }^{13}$

Consider a setting in which $T$ risk-neutral sellers producing horizontally differentiated products compete to fulfill one indivisible contract for a risk-neutral buyer. Seller $i$ 's $\operatorname{cost} c_{i}$ of fulfilling the contract is a privately known independent draw from the commonly known continuous distribution function $G$, with density $g$ that is strictly positive on the interior of the

\footnotetext{
${ }^{12}$ For example, see Tirole [1988, Ch. 7].

${ }^{13}$ Another line of fruitful research would be to evaluate existing models of product differentiation, but that is beyond the scope of our paper. Moreover, in Section 3 we describe how no existing models have all of the features that are relevant to the strategic scenarios we consider.
} 
support $[\underline{c}, \bar{c}]$. The buyer places a privately known value $V_{i}$ on having the contract fulfilled by seller $i$, where each $V_{i}$ is an independent draw from the commonly known continuous distribution function $H$, with density $h$ that is strictly positive on the interior of the support $[\underline{v}, \bar{v}]{ }^{14}$ The players learn their private information before initiating the exchange process.

Exchange is conducted via first-price auctions or nonverifiable multilateral negotiations. In both mechanisms, for a given contract the winning seller's payoff is $p-c_{w}$, where $p$ is the price paid to the winning seller and $c_{w}$ is the winning seller's cost of fulfilling the contract. All other sellers' payoffs are 0 . The buyer's payoff is $V_{w}-p$, where $V_{w}$ is the buyer's value from having the winning seller fulfill the contract. Efficiency is $\left(V_{w}-c_{w}\right) / \operatorname{Max}_{i}\left[V_{i}-c_{i}\right]$ if $\operatorname{Max}_{i}\left[V_{i}-c_{i}\right]$ $>0$, and otherwise is undefined.

In a first-price auction the sellers simultaneously and secretly submit price offers. The seller offering the buyer the largest payoff wins the contract and is paid the price that it offered, conditional on that payoff being positive. That is, seller $i$ wins and is paid price $p_{i}$ if $V_{i}-p_{i}>$ $\operatorname{Max}_{j \neq i}\left[0, V_{j}-p_{j}\right]$. In the case of ties, the winner is selected at random from the set of sellers whose offers yield the buyer its greatest positive payoff.

In a nonverifiable multilateral negotiation the sellers simultaneously and secretly submit initial price offers. The buyer can accept one initial offer or reject them all. If the buyer rejects all initial offers, then it can individually engage each seller in non-binding discussions concerning further concessions. A seller has no information about other sellers' offers, so it cannot verify any claims the buyer makes about the attractiveness of those offers. ${ }^{15}$ At any time each seller can make a new offer by reducing its price from its current offer. Importantly, each

\footnotetext{
${ }^{14}$ The homogeneous product setting considered by Thomas and Wilson [2002, 2005] corresponds to the distribution $H$ being degenerate at a specific value.

${ }^{15}$ This contrasts with the verifiable multilateral negotiations considered in Thomas and Wilson [2005].
} 
seller's best offer remains valid, so the buyer can hold a seller's offer while it searches for a better one. Negotiations continue until agreement is reached or the parties abandon the process.

With homogeneous products Thomas and Wilson [2002] conjectured that the outcomes of nonverifiable multilateral negotiations and first-price auctions would look similar. This conjecture was guided by the following theoretical arguments involving a variant of the "button auction” described by Milgrom and Weber [1982]. Suppose that a price clock declines from a sufficiently high level that all sellers would be willing to fulfill the contract at the starting price. Each seller signals its willingness to supply at the current price by depressing a button, and signals its lowest offer by releasing its button at that price. A seller cannot re-enter the bidding, and it cannot see when its rivals release their buttons. The auction concludes when the last seller releases its button, and that seller is awarded the contract at the price showing on the clock when it released its button. This auction is similar conceptually to nonverifiable multilateral negotiations, because in either institution a seller must be concerned that it is making unnecessary price concessions when it already is winning the competition. Moreover, the button auction is strategically equivalent to a first-price auction. In both auctions, strategies consist of mappings from costs into prices, and seller $i$ is choosing its price to maximize the objective function $\left(p_{i}-c_{i}\right) \operatorname{Pr}\left(p_{i}\right.$ wins $)$.

The evidence with homogeneous products showed the conjectured relationship held only partly. Negotiations and auctions yielded the buyer statistically indistinguishable amounts of surplus with four sellers, but negotiations yielded statistically less surplus than did auctions with two sellers. The difference in duopoly occurred when a seller with especially low costs faced a rival with especially high costs. Even though the sellers' costs were private information, when there was a large gap between their costs the buyer for some reason was unable to extract 
significant concessions from the low-cost seller once the high-cost seller effectively dropped out of the negotiations.

With differentiated products we conjecture that multilateral negotiations will perform relatively better for the buyer than will first-price auctions, because the auction outcomes are likely to be inefficient. ${ }^{16}$ Inefficiency corresponds to lost gains from trade, and we think the communication available with multilateral negotiations will allow the buyer to obtain some of the surplus that would be lost in the auctions.

\section{Related Research}

Although to date no theoretical analyses of multilateral negotiations include all of what we consider to be essential elements of the strategic environment, there is related theoretical and experimental research. Recognizing how that research differs from the setting we consider is important in formulating subsequent analyses. For additional references, please consult Thomas and Wilson [2002, 2005].

The first set of relevant papers involves the trade of homogeneous products through exchange methods featuring aspects of bargaining. Shaked and Sutton [1984] model an alternating offer setting in which the buyer can switch to a different seller after some commonly known length of time. Both sellers have the same commonly known production cost, the buyer can bargain with only one seller at a time, and switching to another seller voids any existing offer. The authors find that the buyer obtains greater surplus than if switching were impossible.

\footnotetext{
${ }^{16}$ First-price auctions are predicted to be $100 \%$ efficient with homogeneous products in our setting. To see from a theoretical perspective why first-price auctions might be inefficient with differentiated products, suppose that sellers set their prices according to a function that is strictly increasing in their privately known production costs. The winning seller will not necessarily be the one with the largest difference between the buyer's value and the seller's cost, because equilibrium price-setting functions likely increase less than one for one with the seller's cost.
} 
McAfee and Vincent [1997] model an auction with a public reserve price, in which the auctioneer cannot commit not to solicit future offers if it rejects all current offers. They show that as the time between offers goes to zero, expected revenues converge to those from a static auction with no reserve price. The inability to forego seeking future offers gives this auction a feel similar to multilateral negotiations, and results such as theirs support conjectures about the similarity of the institutions' outcomes.

Wang [2000] models a procurement setting in which the buyer has the same privately known value for each seller's product, and the sellers have privately known costs. After the sellers make simultaneous price offers, the buyer can reject all offers, accept the lowest offer and pay it, or negotiate with the seller making the lowest offer. The negotiated outcome consists of the equilibrium payoffs from an alternating offers bargaining model with one-sided incomplete information, because the author assumes that the seller's cost becomes common knowledge once negotiations commence.

Cason, Friedman, and Milam [2003] experimentally evaluate a trading environment in which several sellers and buyers engage in bilateral negotiations that start from the seller's list price. A buyer can abandon negotiations with one seller by incurring a cost to initiate negotiations with another seller. The authors find that efficiency is lower and prices are higher in this setting than in a posted offer environment.

The next set of relevant papers considers the trade of differentiated products through various auction formats. Che [1993] models "scoring" auctions in which sellers make pricequality offers to a buyer who evaluates the offers according to a scoring rule. The main difference between our approach and the literature on scoring auctions is that we assume that 
sellers do not tailor their product to a particular buyer. Whether product differentiation is endogenous or exogenous is an empirical matter specific to the market in question.

Engelbrecht-Wiggans, Haruvy, and Katok [2007] theoretically and experimentally analyze a procurement setting in which the buyer's value for seller $i$ 's product is known by the buyer and by seller $i$, and the sellers have privately known costs. The authors study a "pricebased" mechanism in which the seller offering the lowest price wins the contract at the price that it offered, and a "buyer-determined" mechanism in which the seller offering the highest payoff to the buyer wins the contract at the price that it offered. The latter mechanism is equivalent to the first-price auction in the present paper, but their assumption that a seller knows the buyer's value for its product makes that mechanism isomorphic to a standard auction with homogeneous products. ${ }^{17}$ The auction in our setting is not solvable through similar means.

Rezende [2009] models a duopoly procurement setting in which the buyer can credibly reveal its preferences for the sellers' products. The sellers participate in a dynamic auction in which they observe all existing price offers, and in alternate periods they choose whether or not to cut their existing price offer by a specified amount. The auction concludes if the sellers refrain from cutting price in consecutive periods, after which the buyer can negotiate with one of the sellers. The author finds that the buyer should fully reveal its preferences, but that it may prefer not to learn its actual values for the sellers' products.

\section{Experimental Design and Procedures}

Using Section 2's framework as a guide, for the experiment we pair two treatments, one with 16 first-price auctions and one with 16 nonverifiable multilateral negotiations. We vary

\footnotetext{
${ }^{17}$ Two other differences are that they assume profitable trades always exist, and that the buyer might not select the winner that maximizes its payoff.
} 
these two treatments by changing the number of sellers from two per buyer to four per buyer, which yields four treatments in total.

For each of the four treatments we have four groups of subjects, which we also refer to as sessions. Each subject is assigned a specific role in a specific group for the duration of the experiment. A seller's characteristics consist of 16 privately known random cost draws from the Uniform distribution on the support $[0,600]$ (in cents), one for each time period. Of the eight groups with four sellers, seller $i(i=1,2,3,4)$ has the same cost draws across groups. Of the eight groups with two sellers, seller $i(i=1,2)$ has the same cost draws across groups. Moreover, the costs of sellers 1 and 2 in the two-seller treatment are the same as the costs of sellers 1 and 2 in the four-seller treatment. These design features reduce the variation across subjects, and consequently tighten the standard errors of our estimates.

The buyer's characteristics consist of 16 sets of privately known random preference draws from the Uniform distribution on the support [300, 900]. Each set consists of either two or four draws for each time period, depending on the number of sellers. Analogously to the sellers' costs, the buyers in all 16 groups have the same preference draws for seller $i(i=1,2,3,4)$.

The presence of product differentiation is the difference between the environment in this experiment and the one reported in Thomas and Wilson [2002]. In that experiment the buyer's value for each seller's product was commonly known to be 600 , while here the unbiased expectation of the buyer's value is 600. Consequently, a transaction between the buyer and a randomly chosen seller has the same expected total surplus in both environments, but introducing product differentiation increases expected total surplus from the surplus-maximizing transaction.

The first-price auction proceeds with each seller simultaneously submitting a price offer, at which point the winner is determined as described in Section 2. The nonverifiable multilateral 
negotiation proceeds with each seller simultaneously submitting an initial price offer. If the buyer rejects all initial offers, the negotiations are implemented by the buyer engaging in nonbinding text messaging with each seller over the computer network. The buyer cannot credibly reveal to a seller its preferences or the other sellers' offers. Sellers can respond to these communications by making lower price offers, the buyer can accept or reject these new offers, and so on. Each seller's best offer remains valid while the negotiations are conducted, so seeking better offers does not void existing ones.

Participants, undergraduate students recruited from the general student population of a large state university, received $\$ 5$ for showing up on time, plus their salient earnings. In the four-seller sessions the buyers’ exchange rate was US\$1 for 7 experimental dollars, and the sellers’ exchange rate was US\$1.50 for 1 experimental dollar. In the two-seller sessions the respective exchange rates were 4 and 2 experimental dollars for each US\$1. In addition to the \$5 show-up payment, the average subject earned $\$ 19.17$. The average session lasted 90 minutes.

\section{Experimental Results}

For each period we observe the transaction price, the buyer's value for each seller's product, each seller's cost, each seller's offer in the auctions, and each seller's initial and subsequent offers in the multilateral negotiations. We analyze the data using a linear mixedeffects model for repeated measures, ${ }^{18}$ and we pool the data from the present experiment with the data from Thomas and Wilson [2002] that considers homogeneous products. ${ }^{19}$ Combining the

\footnotetext{
${ }^{18}$ See Longford [1993] for a description of this technique commonly employed in experimental sciences.

${ }^{19}$ In particular, we use the data from the first twelve periods of the experiment described in Thomas and Wilson [2002]. That experiment used a crossover design, and so the outcomes following a change from one institution to another are not directly comparable to the outcomes in the present experiment.
} 
data permits parsimonious comparisons across institutions within a differentiation regime, and within institutions across differentiation regimes.

\subsection{Differentiation's Effect on Surplus Comparisons Across Institutions}

We focus our attention on the buyer's surplus rather than on the transaction price, because prices do not provide a meaningful way to compare settings with and without product

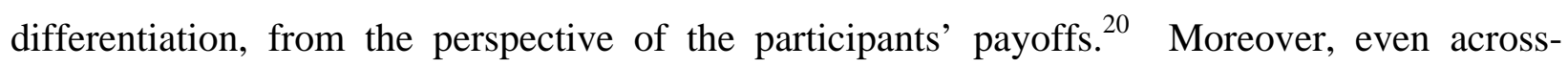
institution comparisons using prices may be misleading in settings with product differentiation. For example, auctions may lead to higher transaction prices but higher buyer's surplus, if in the auctions the buyer more frequently purchases from the seller whose product has the highest intrinsic value. In that case the buyer would prefer the exchange mechanism with higher prices.

Table 1 reports the model's regression results, with the buyer's surplus as the dependent variable. The treatment effects (Two vs. Four Sellers, Nonverifiable Multilateral Negotiation vs. First-Price Auction, and Differentiation (D) vs. Homogeneous Products) and the two- and threeterm interaction effects from a $2^{3}$ design are modeled as (zero-one) fixed effects. The 32 independent sessions are modeled as random effects, $e_{i}$. Following Thomas and Wilson [2002], we control for across-period surplus variation by including period-specific deviations of the highest and second-highest surpluses from their theoretical expected values. We denote those deviations by $s_{1}$ and $s_{2}{ }^{21}$ This formulation captures each treatment's expected buyer's surplus in the treatment coefficient, because on average $s_{1}=s_{2}=0$. Specifically, we estimate the model

\footnotetext{
${ }^{20}$ The results in Thomas and Wilson [2002] regarding transaction prices with homogeneous products can be easily translated into surplus terms, because the buyer's value for all sellers' products is a known constant.

${ }^{21}$ With homogeneous products and two sellers, the expected values of the highest and second-highest surpluses are 400 and 200. With four sellers the expected values are 480 and 360. With horizontally differentiated products and two sellers, the expected values are 440 and 160. With four sellers the expected values are 554.524 and 376.429.
} 


$$
\begin{aligned}
\pi_{i j}^{B}= & \mu+e_{i}+\beta_{1} \text { Two }_{i}+\beta_{2} \text { Negotiation }_{i}+\beta_{3} \text { Two }_{i} \times \text { Negotiation }_{i}+ \\
& \beta_{4} s_{1 i j}+\beta_{5} s_{1 i j} \times \text { Two }_{i}+\beta_{6} s_{1 i j} \times \text { Negotiation }_{i}+\beta_{7} s_{1 i j} \times \text { Two }_{i} \times \text { Negotiation }_{i}+ \\
& \beta_{8} s_{2 i j}+\beta_{9} s_{2 i j} \times \text { Two }_{i}+\beta_{10} s_{2 i j} \times \text { Negotiation }_{i}+\beta_{11} s_{2 i j} \times \text { Two }_{i} \times \text { Negotiation }_{i}+ \\
& \beta_{12} D+\beta_{13} D \times \text { Two }_{i}+\beta_{14} D \times \text { Negotiation }_{i}+\beta_{15} D \times \text { Two }_{i} \times \text { Negotiation }_{i}+ \\
& \beta_{16} D \times s_{1 i j}+\beta_{17} D \times s_{1 i j} \times \text { Two }_{i}+\beta_{18} D \times s_{1 i j} \times \text { Negotiation }_{i}+\beta_{19} D \times s_{1 i j} \times \text { Two }_{i} \times \text { Negotiation }_{i}+ \\
& \beta_{20} D \times s_{2 i j}+\beta_{21} D \times s_{2 i j} \times \text { Two }_{i}+\beta_{22} D \times s_{2 i j} \times \text { Negotiation }_{i}+\beta_{23} D \times s_{2 i j} \times \text { Two }_{i} \times \text { Negotiation }_{i}+\varepsilon_{i j}
\end{aligned}
$$

where $\pi_{i j}^{B}$ denotes the buyer's surplus in period $j$ of session $i$, with $e_{i} \sim N\left(0, \sigma_{1}^{2}\right)$ and $\varepsilon_{i j} \sim N\left(0, \sigma_{2, i}^{2}\right){ }^{22}$ We accommodate heteroskedastic errors by session when estimating the model via maximum likelihood.

Estimates of the treatment effects are easy to compute with this specification. The buyer's expected surplus is $\mu$ in a four-seller first-price auction with homogeneous products, $\mu+$ $\beta_{12}$ in a four-seller first-price auction with differentiated products, $\mu+\beta_{2}$ in a four-seller nonverifiable multilateral negotiation with homogeneous products, and so forth. Across-treatment surplus differences, and differences-in-differences, also are easy to compute.

For comparison purposes, we begin by restating a central finding from Thomas and Wilson [2002] regarding the buyer's surplus with homogeneous products.

Finding 0: Consider the setting with homogeneous products. With two sellers the buyer's surplus when using multilateral negotiations is significantly lower than when using first-price auctions. In contrast, with four sellers the buyer's surplus is statistically indistinguishable when using multilateral negotiations and first-price auctions.

\footnotetext{
${ }^{22}$ It is important to note that the linear mixed-effects model for repeated measures treats each session as one degree of freedom with respect to the treatments.
} 
Evidence: With two sellers the sum of the coefficients on Negotiation and Two $\times$ Negotiation on the left side of Table 1 represents the amount by which the negotiation treatment changes the buyer's surplus relative to first-price auctions. The negotiation treatment significantly decreases the buyer's surplus by $104.6(=-3.1-101.5)$ experimental cents below its level in first-price auctions ( $p$-value $=0.0001)$. With four sellers the point estimate of the negotiation treatment is economically small $(-3.1)$ and statistically insignificant $(p$-value $=0.8746)$.

Our explanation of Finding 0 comprises part of our explanation of Finding 1, so we postpone it briefly. To begin our analysis of product differentiation, we evaluate the buyer's surplus across institutions.

Finding 1: Consider the setting with horizontally differentiated products. With a given number of sellers, the buyer's surplus is statistically indistinguishable when using multilateral negotiations and first-price auctions.

Evidence: The estimates in Table 1 provide the evidence for this finding. With two sellers the difference between the buyer's surplus in the negotiations and the auctions is 12.4 (= -3.1 - 101.5 $+4.7+112.3)$ and insignificant ( $p$-value $=0.5416$ ), as given by the sum of the coefficients on Negotiation, Two $\times$ Negotiation, Differentiated $\times$ Negotiation, and Differentiated $\times$ Two $\times$ Negotiation. With four sellers the difference is $1.6(=-3.1+4.7)$ and insignificant $(p$-value $=$ 0.9352), as given by the sum of the coefficients on Negotiation and Differentiated $\times$ Negotiation . 
Unlike with homogeneous products, a buyer facing two sellers does not receive higher surplus with first-price auctions than with multilateral negotiations. This relative improvement for the buyer in the negotiations' performance suggests that the buyer can better exploit its privately known preferences as a result of the communications allowed by the multilateral negotiations. Moreover, this finding is consistent with our hypothesis that multilateral negotiations' prevalence stems in part from aspects of strategic environments that are absent from earlier analyses.

In Section 2 we conjectured that introducing product differentiation would yield a relative improvement in the buyer's surplus from negotiations over auctions, because negotiations may capture gains from trade lost by the auctions. To evaluate this explanation for Finding 1, we would like to estimate product differentiation's effect on efficiency. However, efficiency in each period is so consistently high in all sessions that there is insufficient variation to estimate a linear mixed-effects model for the ratio of realized total surplus to maximum available surplus. Instead we provide suggestive evidence about efficiency by comparing the expected value of the highest total surplus to the sum of the estimated values of the buyer's surplus and the sellers' surplus. Table 2 reports estimates of the winning seller's surplus, using the same linear mixed-effects approach with which we estimated the buyer's surplus in Table 1 . These estimates in fact reflect the sum of the sellers' surpluses, because losing sellers earn zero.

Table 3 reports the sum of the estimated buyer's surplus and winning seller's surplus as a fraction of the expected maximum total surplus. Efficiency is high in all treatments, and there is no obvious economically significant change from introducing product differentiation. This evidence suggests that the negotiations' relative performance improvement is not driven by inefficiency in the first-price auctions when there is product differentiation. 
Another possible explanation for Finding 1 begins by noting that product differentiation does not obviously affect the original intuition for the conjectured relationship between firstprice auctions and nonverifiable multilateral negotiations. As we described in Section 2, Thomas and Wilson [2002] argued that a seller in nonverifiable multilateral negotiations with homogeneous products must be concerned that the buyer is lying about the seller's current standing in the competition. This concern translates into decisions about what pricing concessions to make, and those relate to pricing incentives in auction formats that are strategically equivalent to first-price auctions. Specifically, seller $i$ in the negotiations essentially is choosing a "stopping price" $p_{i}$ to maximize $\left(p_{i}-c_{i}\right) \operatorname{Pr}\left(p_{i}\right.$ wins $)$, which has the same form as the seller's objective function in a first-price auction. A seller's objective function has the same form with differentiated products, although the probability of winning depends on prices and the buyer's values for the sellers' products. This perspective suggests the same link between auctions and negotiations, whether products are homogeneous or differentiated. ${ }^{23}$

As described in Finding 0, the observed behavior with homogeneous products partly supported the conjectured relationship. Thomas and Wilson [2002] show that the departure occurred in duopoly when one seller had particularly low costs and the other seller had high costs. In such cases it appears that the buyer was unable to obtain significant concessions from the low-cost seller in the negotiations. With four sellers the buyer's ability presumably is less relevant, because the difference between the lowest and second-lowest costs on average is smaller than when there are only two sellers.

Finding 1 shows that the across-institution difference disappears with differentiation. Given that the difference with homogeneous products appeared for particular realizations of the

\footnotetext{
${ }^{23}$ Note that we are not suggesting, for example, that the Bayesian Nash equilibrium in a first-price auction is the same with homogeneous and differentiated products. By considering the pricing behavior of a seller with the highest possible cost draw, one can easily show that the equilibria must differ.
} 
sellers' costs, the difference with differentiated products may disappear in the same instances. Figure 1 supports this explanation by plotting transaction prices against each period's lowest realized cost. The top two panels show average transaction prices in each period for each institution, with homogeneous products. The left panel represents the setting with two sellers, and the right the setting with four sellers. With two sellers the difference in outcomes between the auctions and the negotiations is evident by the gap in the linear trend lines when the lowest realized cost is less than 225. With four sellers the similarity in outcomes across institutions is equally apparent for all lowest realized costs. The bottom two panels include the trend lines from the top two panels, overlaid by the data and linear trend lines for each institution with differentiated products. As is evident, introducing product differentiation lowers transaction prices in the two-seller nonverifiable multilateral negotiations precisely when the lowest realized cost is quite low.

The change in the sellers' pricing behavior may stem from a low-cost seller's reduced likelihood of being the buyer's surplus-maximizing trading partner. That is, low costs are less of a guarantee that the seller is going to make a sale with differentiated products, because the buyer may have a low intrinsic value for that seller's product and a high intrinsic value for the other seller's product. Therefore, a low-cost seller may be more easily persuaded to offer price concessions when there is differentiation. If so, this may serve to mitigate the buyer's unexpected bargaining handicap that was observed with homogeneous products.

\subsection{Differentiation's Effect on Sellers' Pricing Behavior}

While Findings 0 and 1 illustrate the change in the relative performance of auctions and negotiations, considering how that change comes about may deepen our understanding of how 
product differentiation changes behavior in the two institutions. That is, while we know that introducing product differentiation with two sellers causes the negotiations to become relatively more competitive than the auctions, is this due to more intense competition in the negotiations, less intense competition in the auctions, or some other change?

In the next finding we address this issue by measuring the intensity of competition in each treatment. While there are many ways one might attempt to measure competition, care must be taken to account for changes that arise simply because expected surplus is greater in the settings with product differentiation, or from other effects of changing the strategic environment.

Our measure of the intensity of competition includes the buyer's realized surplus in a period, $\pi^{B}$, as a fraction of the maximum total surplus possible that period, $S_{1}$. Identifying what fraction of the available surplus the buyer receives, rather than just the amount of surplus received, accounts for increases in the buyer's surplus that may occur solely because greater total surplus is available with product differentiation. That is, the buyer's surplus may increase even if the sellers become less competitive, with the end result that the buyer receives relatively less of the available surplus. We use the maximum possible surplus rather than actual realized surplus (the sum of the buyer's and sellers' surplus) to account for efficiency losses that may occur. With this approach, two transactions with the same buyer's and sellers' surplus will have different measures of competition if one transaction is more efficient than the other. That is, we characterize an efficiency loss as a symptom of decreased competition among the sellers.

We then subtract from $\frac{\pi^{B}}{S_{1}}$ the predicted buyer's surplus in a period as a fraction of maximum total surplus possible that period, when using an efficient exchange mechanism for which competition among the sellers does not change across treatments. Specifically, we use the buyer's surplus that would emerge in a "second-surplus" auction in which the sellers have a 
dominant strategy of setting their price equal to their cost in both the homogeneous product and differentiated product settings. The buyer's surplus in this auction is the second-highest level of surplus possible, which we denote by $S_{2}$. Consequently, our measure of the intensity of competition for a specific period's values and costs is $\frac{\pi^{B}-S_{2}}{S_{1}}$.

We use the preceding approach to account for changes in the buyer's surplus that emerge simply through changes in the strategic environment that do not lead to changes in the sellers' behavior. To illustrate the issue, consider a duopoly procurement setting with homogeneous products in which the sellers' costs are uniformly distributed from 0 to 600 , the buyer's value for the sellers' product is 1000, and first-price auction rules are used. In equilibrium, the expected price equals the expected value of the second-lowest cost, 400 . The average buyer's surplus is 75 percent of the average available total surplus. If we modify the setting by shifting the costs up by 300, then the sellers' equilibrium price offers shift up by 150 and the expected price is 700 . While there arguably is no change in the intensity of competition between the sellers, the average buyer's surplus is only 60 percent of the average available total surplus. By subtracting the buyer's surplus in a second-price auction (a specific version of a second-surplus auction when products are homogeneous), in both settings the measure of competition is 0 .

Finding 2: Consider moving from homogeneous products to horizontally differentiated products, holding fixed the number of sellers and the institution. With two sellers the intensity of competition increases when using multilateral negotiations, and to a lesser extent when using first-price auctions. With four sellers there is no change in the intensity of competition when using multilateral negotiations or first-price auctions. 
Evidence: The estimates in Table 4 provide the evidence for this finding. With two sellers, introducing differentiation in multilateral negotiations significantly increases our competition measure by $0.771(=0.064+0.495+0.000+0.212)(p$-value $<0.0001)$, while doing so in firstprice auctions significantly increases it by $0.559(=0.064+0.495)(p$-value $<0.0001)$. The difference in the change between the institutions is 0.212 and is significant ( $p$-value $=0.0146$ ). With four sellers, introducing differentiation in multilateral negotiations insignificantly increases our competition measure by $0.064(=0.064+0.000)(p$-value $=0.1322)$, while doing so in firstprice auctions also insignificantly increases it by $0.064(p$-value $=0.1241)$. The changes with four sellers in the negotiations and the auctions are statistically indistinguishable.

Finding 2 shows that introducing horizontal product differentiation equalizes the buyer's surplus across institutions by increasing or leaving unchanged the intensity of competition among the sellers. This result merits further scrutiny because it contrasts with the conventional wisdom that product differentiation softens competition.

One possibility is that the sellers act collusively with homogeneous products, but not with differentiated products. Such behavior would be consistent with the conventional wisdom in the industrial organization literature that collusion is more difficult to sustain when products are differentiated. However, Table 3's reported high efficiency with homogeneous products does not support this explanation. Collusion in procurement by sellers who cannot communicate with each other involves inefficiency, because the sellers cannot tell who has the lowest cost. $^{24}$ Consequently, there is an efficiency loss when the wrong seller is allowed to win the contract.

Another possibility suggested to us is that the sellers actually have become more homogeneous following the introduction of asymmetric information about the buyer's values, in

\footnotetext{
${ }^{24}$ See McAfee and McMillan [1992].
} 
which case the increased intensity of competition is not so counterintuitive. The idea of greater homogeneity is based on the fact that a seller with low costs is less sure it is the buyer's surplusmaximizing choice, while a seller with high costs is less sure it is not. That is, for given cost realizations the sellers now hold more similar beliefs about the likelihood of their being the buyer's surplus-maximizing trading partner. The problem with this explanation is that despite the "flattening out" of the beliefs, the sellers actually are more differentiated. For example, footnote 21 reports that introducing product differentiation increases the difference between the expected highest and second-highest levels of surplus, which is the difference in expected surplus offered by the best and second-best trading partners. ${ }^{25}$

A third explanation for Finding 2 is that non-collusive equilibrium behavior in this setting becomes more competitive after introducing product differentiation, in contrast to what is typically seen in other oligopoly models. Although the derivation of equilibrium solutions for models of auctions and multilateral negotiations in this setting is an open problem, ${ }^{26}$ to assess this possibility we numerically approximate the sellers' Nash equilibrium price-setting function in a first-price auction using the parameters from the experiment: The sellers' privately known costs are uniformly distributed from 0 to 600, and the buyer's privately known values are uniformly distributed from 300 to 900 . Appendix A describes the approximation techniques.

Each panel of Figure 2 plots with a smaller dashed line the equilibrium price-setting functions for first-price auctions, either the analytically derived one when products are homogeneous or the numerically derived one when products are differentiated. As is evident from comparing the panels horizontally, introducing product differentiation leads to higher equilibrium price offers by sellers, for all cost realizations. Moreover, calculation of the

\footnotetext{
${ }^{25}$ A similar argument can be made regarding the variance of the difference between two sellers' surplus as the buyer's trading partner.

${ }^{26}$ Appendix B responds to various critical comments to this and other facts.
} 
competition measure $\frac{\pi^{B}-S_{2}}{S_{1}}$ shows that competition gets less intense after introducing product differentiation, exactly as the conventional wisdom suggests. In our numerical approximation, the measure is -0.084 with two sellers, and is -0.112 with four sellers. That is, after introducing product differentiation the buyer gets a smaller share of the available surplus, relative to a benchmark in which the intensity of competition is unchanged.

To see how subjects' behavior relates to theoretical predictions, the wider dashed and solid lines in each panel of Figure 2 replicate the linear trend lines from Figure 1 for the observed transaction prices in the first-price auctions in the experiment. The trend lines show that prices are lower than predicted with homogeneous products, but more importantly that they do not increase with differentiated products. As we mentioned in our discussion of Figure 1, a possible explanation for this behavior is that low-cost sellers are concerned they are not the buyer's surplus-maximizing trading partner when products are differentiated. Comparing the experimental results with the numerically approximated equilibrium suggests the sellers overcompensate for this additional uncertainty, in a manner that suggests the buyer receives an informational rent from its privately known preferences for the sellers' products.

In summary, Findings 1 and 2 jointly demonstrate that adding uncertainty for the sellers intensifies competition amongst them in both trading formats, to the buyer's benefit. Wilson and Zillante [2010] find similar effects from uncertainty in a laboratory experiment with sixteen buyers facing four sellers, each of whom is privately informed about the quality of its products. If the sellers post flexible, take-it-or-leave-it prices that are publicly observed by all buyers and all sellers, rip-offs prevail that are associated with the classic lemons story: low-quality sellers overwhelmingly stock out at prices far greater than the buyer's value for the low-quality product. If the sellers' posted prices instead are observed only by buyers who sequentially visit the sellers, 
separating outcomes occur: low-quality products sell at low prices, and high-quality products sell at high prices. The authors conclude that “the buyers' uncertainty as to whether or not a seller is peddling a lemon is completely and remarkably counterbalanced by a corresponding uncertainty on the other side of the market as to what are the competing market prices.”

\section{Conclusion}

In this paper we find that introducing product differentiation into a standard procurement setting can affect sellers' pricing behavior in a way that changes the relative performance rankings of auctions and multilateral negotiations. With two sellers the buyer's surplus is equal in the auctions and the negotiations when products are differentiated, while surplus in the auctions is higher than in the negotiations when products are homogeneous. With four sellers we find that differentiation leads to no change in the institutions' relative performance rankings, so that auctions and multilateral negotiations continue to yield the buyer equal surplus. The equivalence we find after introducing differentiation helps explain the prevalence of multilateral negotiations despite the earlier findings with homogeneous products that suggested buyers would tend to prefer auctions.

We also investigate how the sellers' behavior changes as we introduce product differentiation, which provides insights into how the institutions' relative performance rankings are influenced. With two sellers we find that competition becomes more intense in both the auctions and the negotiations, while with four sellers there is no change in the intensity of competition. Both findings contrast with the typical intuition from standard oligopoly models, and with the prediction from a numerical approximation of equilibrium pricing in a first-price auction with differentiated products. This unexpected finding may be due to a low-cost seller's 
willingness to offer concessions when faced with uncertainty about whether it is the surplusmaximizing trading partner. When the buyer's value is the same for all sellers' products, a lowcost seller is more confident that it will ultimately make the sale.

\section{Appendix A}

In this appendix we describe the iterative procedure by which we numerically approximate the sellers' Nash equilibrium price-setting functions in a first-price auction with horizontally differentiated products. We evaluate the same 2-seller and 4-seller settings as in the experiment: the sellers' costs are Uniformly distributed from 0 to 600 , and the buyer's values are Uniformly distributed from 300 to 900.

We solve for a symmetric equilibrium from the perspective of seller 1 . Our iterative approach begins by finding seller 1's best-response to an initial price-setting function used by seller 1's rivals. In the next iteration seller 1's rivals use the best-response function derived in the prior step, and we find seller 1's best-response to that. The procedure stops when seller 1's best-response function is within a given distance of the rivals' price-setting function, and seller 1's final best-response function is our approximation of the equilibrium price-setting function.

Given how seller 1's rivals set prices, seller 1's best-response for each cost $c$ is the price $p$ that maximizes $(p-c) \operatorname{Pr}(p$ wins). The probability function depends on the rivals' price-setting function, and that probability function's nature creates the difficulty in deriving analytic equilibrium solutions. Roughly speaking, with homogeneous products the probability a particular price wins is a length, while with differentiated products the probability is an irregularly shaped volume. 
We approximate the probability function in seller 1's objective function in the following manner. Given the rivals' price-setting function, we take two million random draws of values and costs for each rival, and of values for seller 1 . We discretize the price space, and for each price $p$ in $\{0,1,2, \ldots, 900\}$ the probability that $p$ wins is the fraction of the two million cases in which with price $p$ seller 1 offers the buyer a positive payoff that exceeds the payoff from the rivals.

We approximate seller 1's best-response to its rivals' price-setting function in the following manner. We discretize the cost space, and for each cost $c$ in $\{0,5,10, \ldots, 600\}$ we find the price in $\{0,1,2, \ldots, 900\}$ that gives seller 1 the highest expected payoff.

Having found seller 1's best-response at a discrete set of costs, we fit a cubic to those points. The fitted cubic is set as the rivals' price-setting function, and we repeat the procedure described above. We use the same set of value and cost draws for each iteration. The procedure concludes when the maximum difference between the rivals' price-setting function and seller 1's best-response is less than 1 , evaluated at each cost in $\{0,5,10, \ldots, 600\}$. The procedure converged in fewer than 10 iterations, and with different initial price-setting functions the process converged to approximately the same price-setting function.

With the approximated price-setting function in hand, we used the same random draws to calculate our measure of the intensity of competition. 


\section{References}

Anderson, S., de Palma, A., and Thisse, J.F. (1992). Discrete Choice Theory of Product Differentiation. (Cambridge and London: MIT Press).

Banks, J., Olson, M., Rassenti, S., Smith, V. (2003). “Theory, Experiment and the Federal Communications Commission Spectrum Auctions,” Journal of Economic Behavior and Organization 51(3), 303-350.

Cason, T. (1995). “An Experimental Investigation of the Seller Incentives in the EPA's Emission Trading Auction,” American Economic Review 85, 905-922.

Cason, T., Friedman, D., and Milam, G. (2003) "Bargaining Versus Posted Price Competition in Customer Markets,” International Journal of Industrial Organization 21, 223-251.

Che, Y.K. (1993). "Design Competition Through Multidimensional Auctions,” RAND Journal of Economics 24(4), 668-680.

Engelbrecht-Wiggans, R., Haruvy, E., and Katok, E. (2007). “A Comparison of BuyerDetermined and Price-Based Multiattribute Mechanisms,” Marketing Science 26(5), 629641.

Fudenberg, D., and Tirole, J. (1983). "Sequential Bargaining with Incomplete Information," Review of Economic Studies 50(2), 221-247.

Kennan, J. and Wilson, R. (1993). “Bargaining with Private Information,” Journal of Economic Literature 31(1), 45-104.

Klemperer, P. (2002). "What Really Matters in Auction Design,” Journal of Economic Perspectives 16(1), 169-189.

Longford, N. T. (1993). Random Coefficient Models. (New York: Oxford University Press).

McAfee, R.P., and McMillan, J. (1987). “Auctions and Bidding," Journal of Economic Literature 25, 699-738.

McAfee, R.P., and McMillan, J. (1992). “Bidding Rings,” American Economic Review 82, 579599.

McAfee, R.P., and Vincent, D. (1997). "Sequentially Optimal Auctions,” Games and Economic Behavior 18, 246-276.

Milgrom, P. (2000). "Putting Auction Theory to Work: The Simultaneous Ascending Auction," Journal of Political Economy 108(2), 245-272.

Milgrom, P., and Weber, R. (1982). “A Theory of Auctions and Competitive Bidding," Econometrica 50, 1089-1122. 
Muthoo, A. (1999). Bargaining Theory with Applications (Cambridge: Cambridge University Press).

Porter, D., Rassenti, S., Shobe, W., Smith, V., and Winn, A. (2009). "The Design, Testing and Implementation of Virginia's NOx Allowance Auction,” Journal of Economic Behavior and Organization 69, 190-200.

Rassenti, S., Smith, V., and Wilson, B.J. (2002) "Using Experiments to Inform the Privatization/Deregulation Movement in Electricity,” The Cato Journal 21(3), 515-544.

Rezende, L. (2009). “Biased Procurement Auctions,” Economic Theory 38, 169-185.

Shaked, A., and Sutton, J. (1984) "Involuntary Unemployment as a Perfect Equilibrium in a Bargaining Model.” Econometrica, 52(6), 1351-1364.

Smith, V.L. (1982). "Microeconomic Systems as an Experimental Science," American Economic Review 72(5), 923-955.

Thomas, C.J., and Wilson, B.J. (2002). "A Comparison of Auctions and Multilateral Negotiations,” RAND Journal of Economics 33(1), 140-155.

Thomas, C.J., and Wilson, B.J. (2005). "Verifiable Offers and the Relationship Between Auctions and Multilateral Negotiations," Economic Journal 115, 1016-1031.

Tirole, J. (1988). The Theory of Industrial Organization. (Cambridge, MA: The MIT Press).

Waehrer, K., and Perry, M. (2003). “The Effects of Mergers in Open-Auction Markets,” RAND Journal of Economics 34 (2), 287-304.

Wang, R. (2000). "Bidding and Renegotiation in Procurement Auctions," European Economic Review 44, 1577-1597.

Wilson, B.J., and Zillante, A. (2010). "More Information, More Ripoffs: Experiments with Public and Private Information in Markets with Asymmetric Information," Review of Industrial Organization 36 (1), 1-16.

Wolfram, C. (1998). "Strategic Bidding in a Multiunit Auction: An Empirical Analysis of Bids to Supply Electricity in England and Wales," RAND Journal of Economics 29, 703-725. 


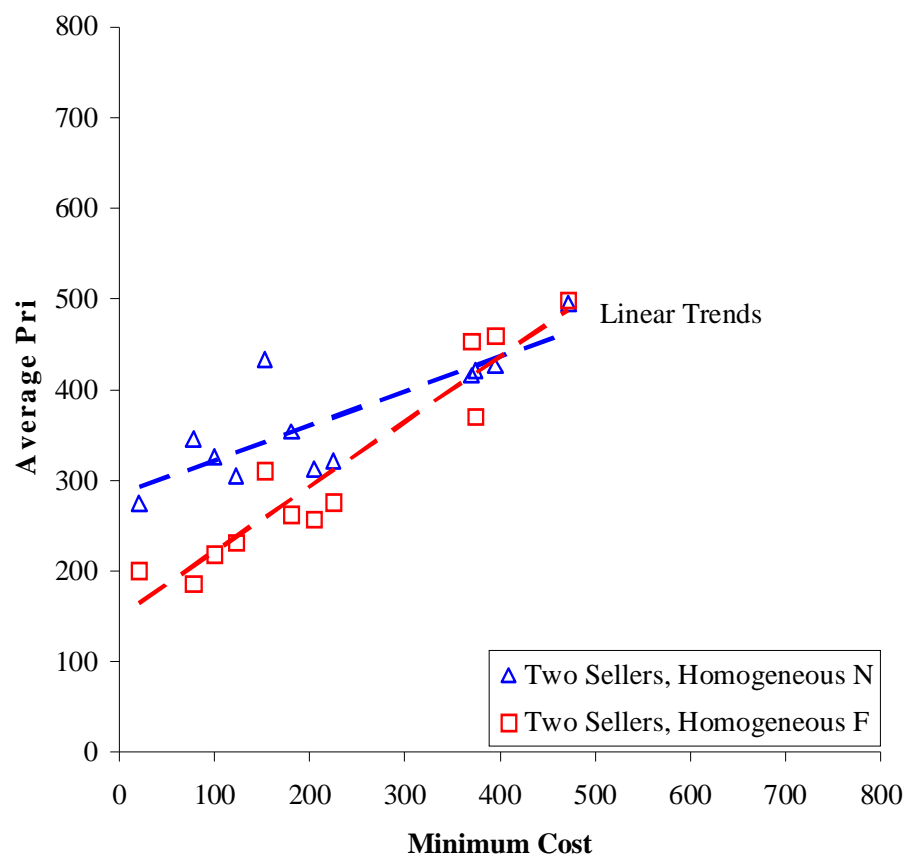

Panel (a). Two Sellers, Homogeneous Products

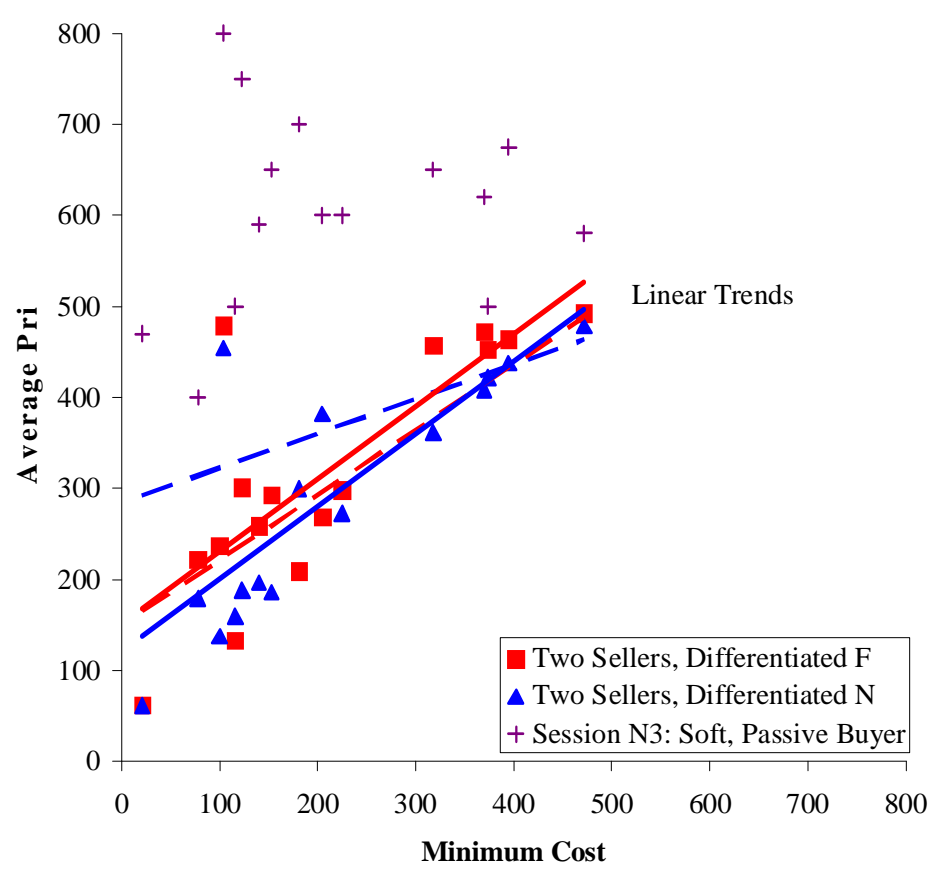

Panel (c). Two Sellers, Differentiated Products

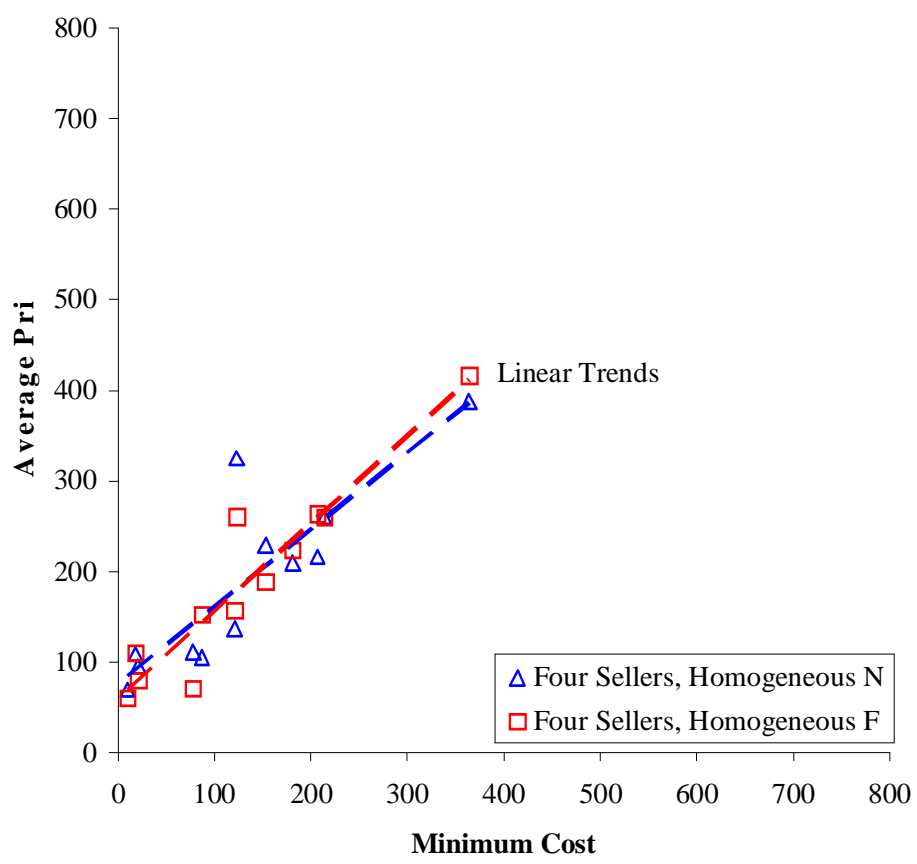

Panel (b). Four Sellers, Homogeneous Products

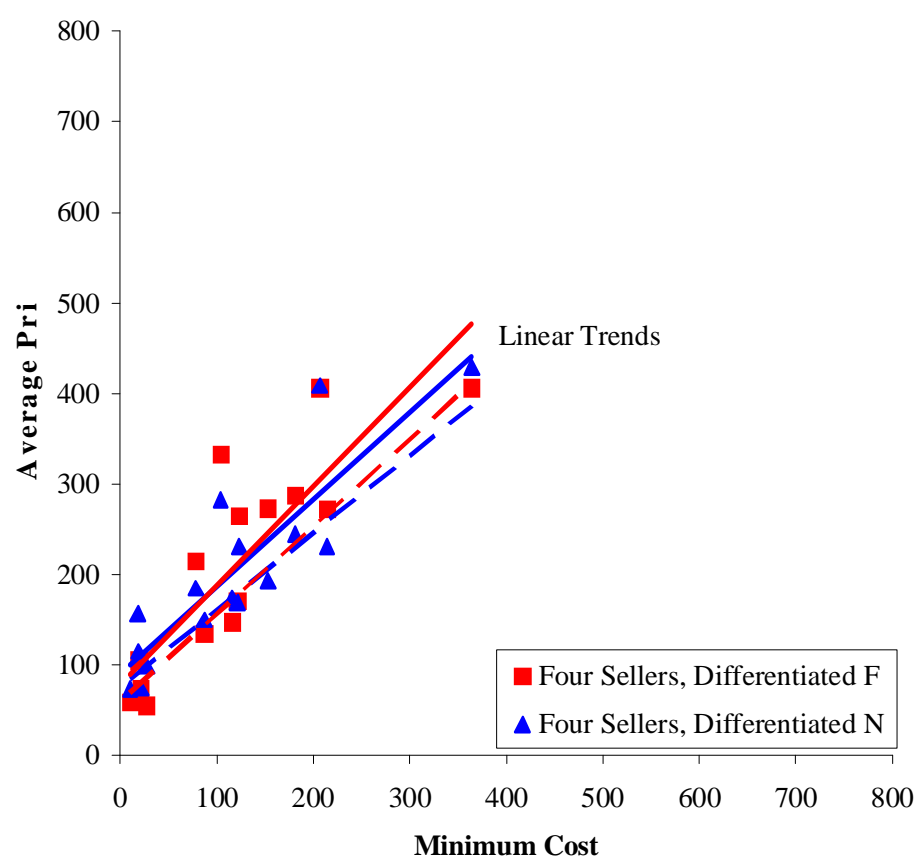

Panel (d). Four Sellers, Differentiated Products

\section{Figure 1. Average Period Prices Versus Minimum Cost}

+While included in the random effects analysis of Tables 1-4, the outlier prices of an unusually soft, passive buyer in a negotiation session are excluded for illustrative purposes from the average price in the panel. 


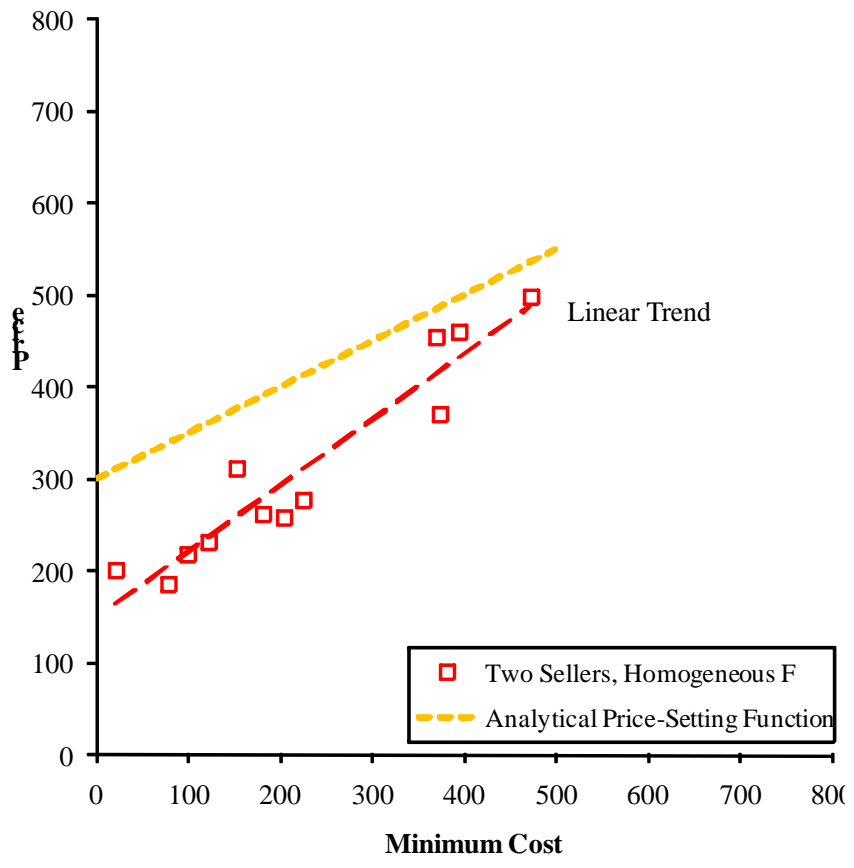

Panel (a). Two Sellers, Homogeneous Products

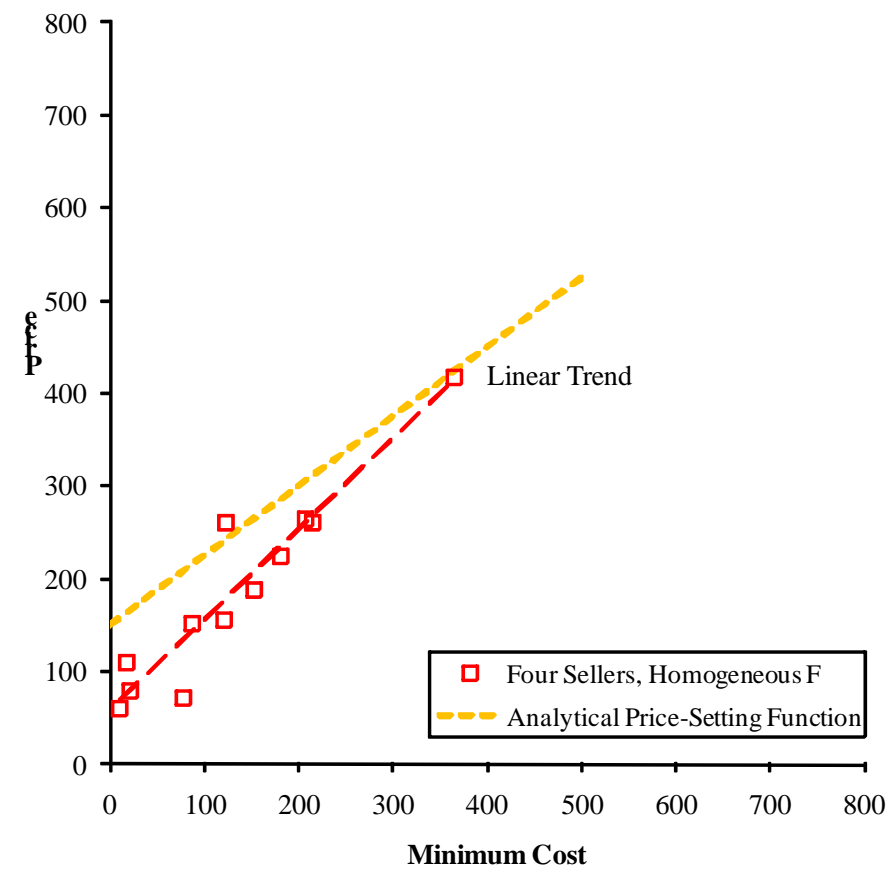

Panel (b). Four Sellers, Homogeneous Products

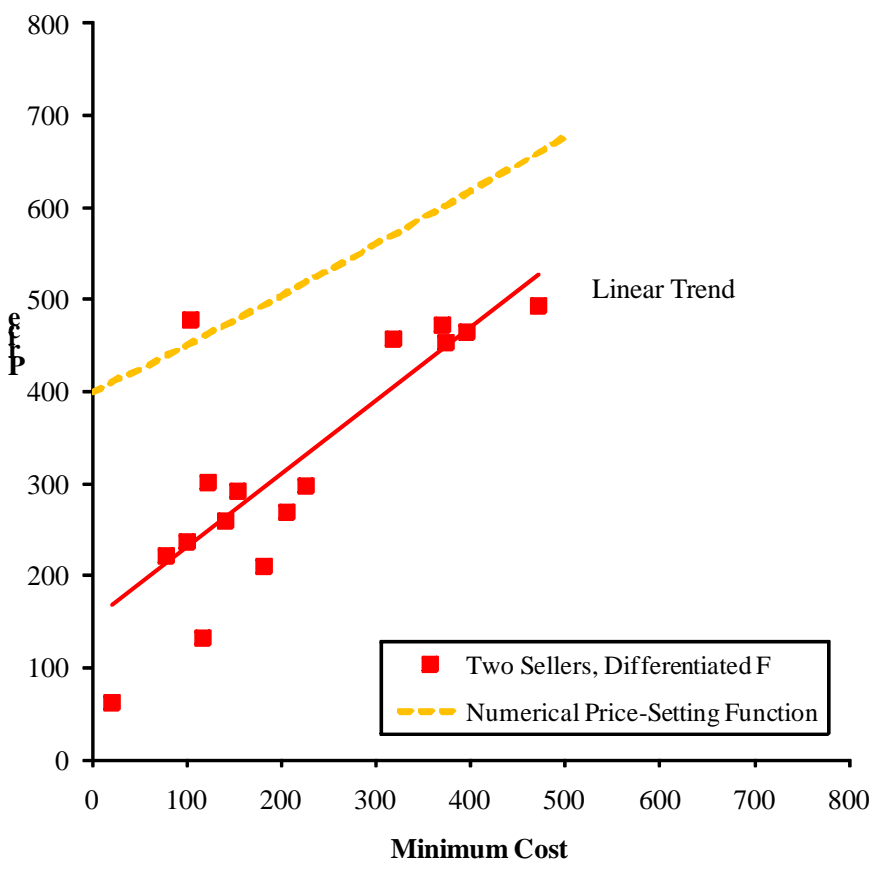

Panel (c). Two Sellers, Differentiated Products

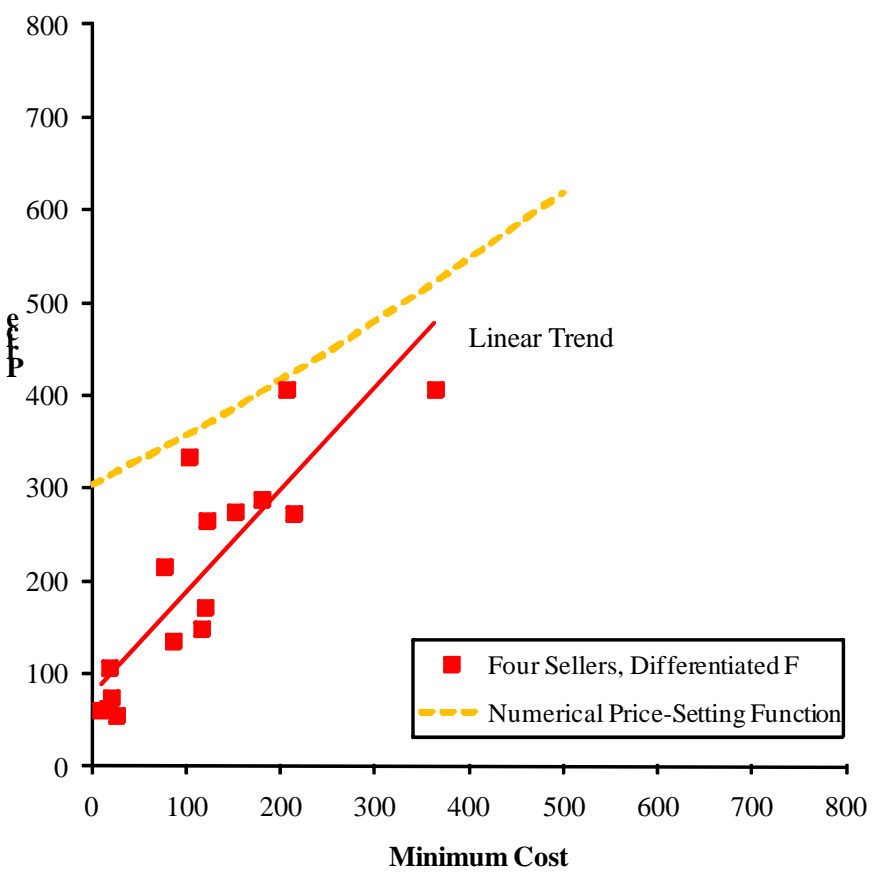

Panel (d). Four Sellers, Differentiated Products

Figure 2. Analytical and Numerical Price-Setting Functions and Observed Average Period Prices 
Table 1. Estimates of the Linear Mixed-Effects Model for Buyer's Surplus

\begin{tabular}{|c|c|c|c|c|c|c|c|c|}
\hline \multirow[b]{2}{*}{$\begin{array}{l}\text { Homogeneous Baseline } \\
\text { (Thomas and Wilson, 2002) }\end{array}$} & \multirow[b]{2}{*}{ Estimate } & \multirow[b]{2}{*}{$\begin{array}{r}\text { Std. } \\
\text { Error }\end{array}$} & \multirow[b]{2}{*}{$\begin{array}{l}\text { Degrees of } \\
\text { Freedom }\end{array}$} & \multirow[b]{2}{*}{$p$-value } & \multicolumn{4}{|c|}{ Dummy Variable for Differentiated $\times$ Baseline } \\
\hline & & & & & Estimate & $\begin{array}{l}\text { Std. } \\
\text { Error }\end{array}$ & $\begin{array}{l}\text { Degrees of } \\
\text { Freedom }\end{array}$ & $p$-value \\
\hline Constant & 424.5 & 13.5 & 400 & $<0.0001$ & 70.3 & 19.7 & 24 & 0.0016 \\
\hline Two & -104.1 & 20.4 & 24 & $<0.0001^{\dagger}$ & -31.9 & 28.4 & 24 & 0.2721 \\
\hline Negotiation & -3.1 & 19.3 & 24 & 0.8746 & 4.7 & 27.8 & 24 & 0.8665 \\
\hline Two $\times$ Negotiation & -101.5 & 28.9 & 24 & 0.0018 & 112.3 & 40.5 & 24 & 0.0105 \\
\hline$s_{1}$ & 1.0 & 0.2 & 400 & $<0.0001$ & 0.0 & 0.2 & 400 & 0.9192 \\
\hline$s_{1} \times T w o$ & -0.2 & 0.2 & 400 & 0.1804 & 0.2 & 0.2 & 400 & 0.2317 \\
\hline$s_{1} \times$ Negotiation & 0.1 & 0.2 & 400 & 0.6542 & 0.0 & 0.3 & 400 & 0.9364 \\
\hline$s_{1} \times$ Two $\times$ Negotiation & -0.6 & 0.2 & 400 & 0.0084 & 0.4 & 0.3 & 400 & 0.1095 \\
\hline$s_{2}$ & 0.0 & 0.1 & 400 & 0.7652 & 0.0 & 0.1 & 400 & 0.7868 \\
\hline$s_{2} \times T w o$ & 0.1 & 0.1 & 400 & 0.3078 & -0.1 & 0.2 & 400 & 0.4237 \\
\hline$s_{2} \times$ Negotiation & -0.2 & 0.2 & 400 & 0.3584 & 0.0 & 0.2 & 400 & 0.8651 \\
\hline$s_{2} \times T w o \times$ Negotiation & 0.1 & 0.2 & $\begin{array}{c}400 \\
448 \text { Obs. }\end{array}$ & 0.5566 & 0.1 & 0.2 & 400 & 0.7761 \\
\hline
\end{tabular}

${ }^{\dagger}$ One-sided test.

Table 2. Estimates of the Linear Mixed-Effects Model for Winning Seller's Surplus

\begin{tabular}{|c|c|c|c|c|c|c|c|c|}
\hline $\begin{array}{l}\text { Homogeneous Baseline } \\
\text { (Thomas and Wilson, 2002) }\end{array}$ & Estimate & $\begin{array}{l}\text { Std. } \\
\text { Error }\end{array}$ & $\begin{array}{l}\text { Degrees of } \\
\text { Freedom }\end{array}$ & $p$-value & Estimate & $\begin{array}{l}\text { Std. } \\
\text { Error }\end{array}$ & $\begin{array}{l}\text { Degrees of } \\
\text { Freedom }\end{array}$ & $p$-value \\
\hline Constant & 36.5 & 11.5 & 400 & 0.0016 & 9.7 & 16.4 & 24 & 0.5611 \\
\hline Two & 36.7 & 18.4 & 24 & $0.0286^{\dagger}$ & -13.3 & 25.4 & 24 & 0.6057 \\
\hline Negotiation & 8.1 & 17.3 & 24 & 0.6417 & -9.8 & 24.2 & 24 & 0.6872 \\
\hline Two $\times$ Negotiation & 84.7 & 26.8 & 24 & 0.0043 & -92.4 & 37.0 & 24 & 0.0196 \\
\hline$s_{1}$ & 0.0 & 0.1 & 400 & 0.8392 & 0.1 & 0.1 & 400 & 0.6155 \\
\hline$s_{1} \times T w o$ & 0.3 & 0.1 & 400 & 0.0088 & -0.3 & 0.1 & 400 & 0.0210 \\
\hline$s_{1} \times$ Negotiation & -0.2 & 0.1 & 400 & 0.2516 & 0.1 & 0.1 & 400 & 0.3977 \\
\hline$s_{1} \times T w o \times$ Negotiation & 0.6 & 0.2 & 400 & 0.0001 & -0.5 & 0.2 & 400 & 0.0095 \\
\hline$s_{2}$ & 0.0 & 0.1 & 400 & 0.9225 & 0.0 & 0.1 & 400 & 0.8503 \\
\hline$s_{2} \times T w o$ & -0.1 & 0.1 & 400 & 0.1850 & 0.1 & 0.1 & 400 & 0.6179 \\
\hline$s_{2} \times$ Negotiation & 0.2 & 0.1 & 400 & 0.0233 & -0.2 & 0.1 & 400 & 0.0768 \\
\hline$s_{2} \times$ Two $\times$ Negotiation & -0.2 & 0.1 & $\begin{array}{c}400 \\
448 \text { Obs. }\end{array}$ & 0.1277 & 0.1 & 0.2 & 400 & 0.3448 \\
\hline
\end{tabular}


Table 3. Sum of Estimated Buyer's Surplus and Winning Seller's Surplus, as a Fraction of Expected Maximum Total Surplus

\begin{tabular}{|c|c|c|}
\hline & Homogeneous Products & Differentiated Products \\
\hline $\begin{array}{c}\text { Four Sellers } \\
\text { First-Price Auctions }\end{array}$ & $96.04 \%$ & $97.56 \%$ \\
\hline $\begin{array}{c}\text { Four Sellers } \\
\text { Multilateral Negotiations }\end{array}$ & $97.08 \%$ & $97.54 \%$ \\
\hline $\begin{array}{c}\text { Two Sellers } \\
\text { First-Price Auctions }\end{array}$ & $98.40 \%$ & $97.36 \%$ \\
\hline $\begin{array}{c}\text { Two Sellers } \\
\text { Multilateral Negotiations }\end{array}$ & $95.45 \%$ & $98.05 \%$ \\
\hline
\end{tabular}

Table 4. Estimates of the Linear Mixed-Effects Model for Buyer's Surplus as a Fraction of Available Total Surplus, Relative to Competitive Benchmark

Homogeneous Baseline (Thomas and Wilson, 2002)

\section{Constant}

Two

Negotiation

Two $\times$ Negotiation $s_{1}$

$s_{1} \times T w o$

$s_{1} \times$ Negotiation

$s_{1} \times T w o \times$ Negotiation

$s_{2}$

$s_{2} \times T w o$

$s_{2} \times$ Negotiation

$s_{2} \times$ Two $\times$ Negotiation

${ }^{\dagger}$ One-sided test.
Std. Degrees of Estimate Error Freedom 0.150

$-0.236$

0.000

$-0.176$

0.001

$-0.001$

0.000

$-0.001$

$-0.002$

0.002

0.000

0.000

0.028

0.047

0.041

0.064

0.000

0.000

0.000

0.001

0.000

0.000

0.000

0.000
400

24

24

24

400

400

400

400

400

400

400

400 448 Obs.
Dummy Variable for Differentiated $\times$ Baseline Std. Degrees of

$\begin{array}{rrcr}\text { Estimate } & \begin{array}{r}\text { Etr. } \\ \text { Error }\end{array} & \begin{array}{c}\text { Degrees of } \\ \text { Freedom }\end{array} & p \text {-value } \\ 0.064 & 0.040 & 24 & 0.1241 \\ 0.495 & 0.068 & 24 & <0.0001 \\ 0.000 & 0.058 & 24 & 0.9992 \\ 0.212 & 0.099 & 24 & 0.0428 \\ 0.000 & 0.000 & 400 & 0.5530 \\ 0.001 & 0.000 & 400 & 0.0406 \\ 0.000 & 0.001 & 400 & 0.9263 \\ 0.001 & 0.001 & 400 & 0.2967 \\ 0.000 & 0.000 & 400 & 0.5331 \\ -0.003 & 0.000 & 400 & <0.0001 \\ 0.000 & 0.000 & 400 & 0.7788 \\ 0.000 & 0.001 & 400 & 0.4873\end{array}$




\section{Appendix B. Comments from Readers and Our Responses (Not for publication)}

Comment: The most critical omission is the lack of theory, and this is surprising. The theory is not that complicated. In the case of the first-price auctions, since the differentiated value of the buyer is unknown to the seller, the optimal bid should be the same as the optimal bid in the homogenous case, as long as the cost distribution is the same. This is because the optimal bid depends only on the profit conditional on winning and the probability of the bid winning. Since the value is unknown to the seller, the probability of winning is not conditioned on it.

The Bayesian equilibrium of our auction setting with differentiation is not the same as in the case of homogeneous products. The simplest way to see this is to recall that the equilibrium pricesetting function with homogeneous products specifies that a seller with the highest possible cost draw sets its price equal to its cost. With either homogeneous or differentiated products, a seller with such a cost draw who sets such a price gets an expected payoff of 0 . With differentiated products, however, a seller with the highest possible cost draw could strictly increase its profits by deviating to a price slightly above its cost. Because of the product differentiation, it now has a positive probability of winning, and hence its expected profit is strictly positive. Thus, the claim is wrong. Perhaps the difficulty associated with the auction we consider explains why it hasn't yet been solved by auction theorists.

Comment: The negotiation treatment is less structured than the first-price auction, but it is dynamic and so a rejection is informative to the seller about its relative quality that is unknown in the first-price auction case. One could derive the optimal bid and buyer surplus in the case where buyer valuation for seller $j$ is privately known to both the buyer and the seller $j$, but not to other sellers. This was done by Englebrecht-wiggans et al., which you cite.

At present there exists no tractable mathematical model of multilateral negotiations with the product differentiation we consider. The suggested model from Englebrecht-Wiggans et al. is for an informational environment that is crucially different from ours, and moreover is a one-shot simultaneous-move model analogous to our auction, not to our multilateral negotiations.

Comment: My major concern is that the paper does not have a theoretical basis.

Because no current mathematical model of multilateral negotiations captures the fundamental features of the bargaining process in our paper, and because for neither institution is there a straightforward, simple solution for the problem of introducing horizontal product differentiation in the familiar and common way that we do, we chose to conduct a heuristic experiment in the laboratory. Smith (1982) advocates heuristic investigations of new environments and institutions, most notably those whose strategic complexity are analytically intractable, because "it is through exploratory probes of new phenomena that attention may be redirected, old belief systems may be reexamined, and new scientific questions may be asked" (p. 942). ${ }^{27}$ A heuristic experiment, as Abraham Kaplan, a philosopher of behavioral sciences explains, is designed "to

\footnotetext{
${ }^{27}$ Smith, V.L. (1982). "Microeconomic Systems as an Experimental Science,” American Economic Review 72(5), 923-955.
} 
generate ideas, to provide leads for further inquiry or to open up new lines of investigation" (1964, p. 149). ${ }^{28}$ Such is our objective here.

This approach is not advocated only by experimental economists. The well-known bargaining theorist Abhinay Muthoo writes that a "primary role of bargaining experiments should be to make new discoveries about bargaining - for example, to identify new forces that may have a significant impact on the bargaining outcome. In that way bargaining experiments can help in the further development of the theory of bargaining" $\left(1999\right.$, p. 342) ${ }^{29}$

Comment: The paper has no theory so there are no predictions or testable hypotheses, so the comparison of the two treatments is not informative.

Despite bold assertions to the contrary, we can learn by comparing our eight treatment conditions, and as Section 5 reports, our experiments teach us something about product differentiation in auctions and negotiation. Dismissing the paper because we do not model what is unformalizable amounts to rejecting the paper's contribution because we are not foolishly looking for our keys under the proverbial light of the lamppost when the keys are somewhere inside a tunnel beyond the reach of the lamppost.

Comment: My main concern is an overall of lack theoretical structure through which to interpret the results.

Science, pace this reader, is as much about observing, identifying, and describing phenomena as it is about testing predictions from tightly drawn mathematical models. What we're doing in this paper is carrying the flashlight of an experiment into the tunnel to shed some light on the facts of multilateral negotiations and horizontal product differentiation.

Comment: An advantage of the approach of the paper is that it builds on prior experimental work and incorporates results from this prior work in its evaluation of treatment effects. The ability to compare the new results to prior work provides a clear picture of the impact of introducing product differentiation into the procurement institution.

\section{Thank you. That was our intention.}

Comment: A disadvantage of the approach of the paper is that the formulation is not consistent with existing theoretical models of procurement with differentiation. As a consequence, theoretical predictions are available for neither auctions nor negotiations.

See p. 3. We introduce horizontal product differentiation into a procurement setting in an empirically relevant way that is widely employed in the industrial organization literature. In footnote 9, we direct the commenter to Anderson, de Palma, and Thisse (1992) in our references.

\footnotetext{
${ }^{28}$ Kaplan, A. (1964). The Conduct of Inquiry: Methodology for Behavioral Science. New York: Chandler Publishing.

${ }^{29}$ Muthoo, A. (1999). Bargaining Theory with Applications. Cambridge: Cambridge University Press.
} 
Comment: My main problem with the paper is that it is unclear to the reader whether one should view the results as surprising: the authors do not discuss in enough detail the predictions that economic theory may make for these games.

Why is "surprise" the benchmark for appreciating our paper? Adam Smith opens his treatise, The History of Astronomy, by delineating three sentiments for internalizing the phenomena of the universe: wonder, surprise, and admiration, where "[w]hat is new and singular, excites that sentiment which, in strict propriety, is called Wonder; what is unexpected, Surprise; and what is great or beautiful, Admiration” (p. 33). ${ }^{30}$ Given the dearth of economic theory on multilateral negotiations, an institution ubiquitous in the naturally occurring economy, our empirical research with horizontal product differentiation is new and singular. Our hope is that the wonder of our results will inspire more theoretical and empirical work on multilateral negotiations, as it has for us.

Comment: I lament the failure to engage in any theoretical grounding.

To privilege a so-called "theory testing" experiment over an exploratory experiment is simply dogmatic and overlooks the inconvenient fact that a mathematical model necessarily abstracts away from the totality of facts precisely because it cannot accommodate every fact.

Comment: Where theoretical considerations are raised this is done in a very loose fashion.

Unless you can fashion a very tight model, we fail to see the relevance of this observation.

Comment: Given that there is no theory, I was a bit confused about what the authors meant with the terms "theory" and "predicted" on the bottom of pages 13 and 19.

The expected value of the total surplus is simple to compute by treatment and period. The equilibrium bidding strategies are not so simple (in auctions with horizontal product differentiation, and in multilateral negotiations).

Comment: Interpreting results is very difficult without a theoretical analysis. If buyer surplus was higher under negotiations than auctions would we have any reason to think this was a general property of the institutions, or confined to the particular parameters studied?

Suppose we were able to solve for the equilibrium strategies. We would still need to implement a test of the theory with a set of "particular parameters" because specificity is the nature of all empirical inquiry. Whether in physics or economics, any empirical inquiry must be concrete in its implementation of an abstract theory. Moreover, the scope of our project cannot include covering the entire parameter space. Instead we vary the institutions and the number of sellers for a given set of parameters to see if we observe any differences in the outcomes, and we design the experiments to be directly comparable to earlier experiments. A paper cannot be expected to cover all dimensions of lines of inquiry.

\footnotetext{
${ }^{30}$ Smith, A. (1795). Essays on Philosophical Subjects. W. P. D. Wightman and J. C. Bryce, eds. Indianapolis: Liberty Fund, 1982.
} 
Comment: I found the way competitiveness is measured quite convoluted. Why not simply base the measurement on price-cost margins?

See p. 19: "While there are many ways one might attempt to measure competition, care must be taken to account for changes that arise simply because expected surplus is greater in the settings with product differentiation, or from other effects of changing the strategic environment" (italics added). In other words, our measure of the intensity of competition is a comparable index across all treatments; a simple price-cost margin is not.

Comment: I don't like appendices such as this one. If a paper is frequently misinterpreted, then probably the paper itself should be edited so that it is easier to understand.

Fair enough, but the operative word in that statement is "probably". Some of the burden in understanding a paper rests with the reader. This appendix is intended to point out the casual and unreflective philosophy of science that undergirds the sometimes dyspeptic comments listed above. It is not intended for publication, but to highlight how easy it is for naysayers to criticize a paper and risk nothing in doing so, and how difficult it is to discover and defend the new.

\section{Appendix C. Experiment Instructions (Not for publication)}

\section{Buyer/Auction/Differentiation}

$<$ page 1>

This is an experiment in the economics of market decision making. Various foundations have provided funds for this research. The instructions are simple, and if you follow them carefully and make good decisions, you may earn a considerable amount of money that will be paid to you in $\mathrm{CASH}$ at the end of the experiment.

In this experiment we are going to create a market in which you will be a buyer of a fictitious good in a sequence of periods.

<page 2>

This is what your screen will look like for the experiment. Notice in the upper left portion of your screen that the row labeled 'Value' has been filled in with numbers. This indicates the value to you of buying a single unit of this good from a particular seller.

Notice that for Seller 1 you have a value of 810 and for Seller 2 the value is 975 . You can only buy one unit from one seller each period.

If you're able to buy (we'll describe the selling process soon), you will receive the difference between your value and the price paid (the market price).

To sum up: Value - Price Paid $=$ Profit.

<page 3> 
Notice that your cash profits depend upon your ability to buy a unit at a price below the values given on your record sheet. Also note that if you buy a unit at a price equal to its value, your profit will be zero. You cannot buy a unit at price greater than your value.

Your earnings will be automatically entered into your record sheet at the close of each period. Earnings (profits) are accumulated over several periods, with your total earnings at the end of the experiment being your total profit over all periods. The 'Summary Information' frame at the bottom of the screen displays your total profit.

<page 4>

In this experiment there are <insert number of sellers> sellers total, each attempting to sell one unit to 1 buyer. You can only purchase one unit each period.

No seller knows what any of your values are. But, you may ask, “How do I buy this good?” Good question. Continue for the answer.

<page 5>

We will now explain the buying procedures in the following periods. The computer will conduct your buying for you.

Let's go through a sample period. Each seller will submit an offer for a unit to sell to you. An 'offer' is the selling price of the seller.

Once all of the offers have been submitted by the sellers, they will be displayed for you in the 'Seller Offer Prices' in the row labeled 'Price'. In this example, Seller 1 submitted an offer of 600 , and Seller 2 submitted an offer of 650.

<page 6>

The computer will choose to purchase from the seller who submitted the offer that yields you your greatest profit. Your record sheet will be filled in as shown for period 1 . In this example you purchased a unit from Seller 2 at a price of 650, yielding a profit of $975-650=325$.

In the event that two or more sellers tie for the greatest profit for the buyer, the computer will select a winner at random.

The column labeled 'Market Type' summarizes how the market price was determined that period. In this case, the 'Best Offer' determined the market price.

<page 7>

Let's review the important items:

(1) The seller who submits the offer with the greatest profit for you will be the only person to sell the unit to you, as long as that price is not greater than your value.

(2) The price you pay is equal to that offer of the seller. 
(3) Your profit is: Value - Paid.

$<$ page $8>$

This is the end of the instructions. If you wish to review the instructions, you may go back at this time. If you feel you now understand the instructions and are prepared to proceed with the actual experiment, click on the 'Start' button. If you have a question that you feel was not adequately answered by the instructions, please raise your hand and ask the monitor before proceeding. Your earnings may suffer if you proceed into the market without understanding these instructions.

\section{Buyer/Multilateral Negotiation/Differentiation}

$<$ pages 1-4; same as above>

<page $5>$

We will now explain the buying procedures. Your job is to attempt to buy a unit of the good in each period by accepting an offer for it. An 'offer' is the selling price offered to you.

Let's go through a sample period. Each period is comprised of two phases.

\section{Phase 1:}

Each seller submits an offer which will be displayed in the row labeled 'Price' in the 'Seller Offer Prices’ tab. In this example, Seller 2 submitted an offer for 800.

<page 6>

After all of the offers have been submitted by the sellers, the period advances to Phase 2 . At any time during Phase 2, you can accept one of the offers and then the period ends. If you accept an offer, then the record sheet will be filled in as shown. The accepted offer will be displayed in the column labeled 'Price Paid' so that you will have a record of the contract prices you accepted.

The rightmost columns in the record sheet will record the history of all the final submitted offers by seller number.

\section{<page 7>}

\section{Phase 2 (continued):}

Instead of immediately accepting one of the seller's offers, you and the sellers have an opportunity to send messages to each other about a transaction. Messages that you send to a seller (and vice versa) can only be read by you and the seller. You can send private messages to any seller. Sellers can only send messages to you; they cannot send messages to each other.

In the tab in the upper right portion of the screen, you can type your message in the line and click on the 'Send' button.

You are free to discuss all aspects of the market, with the following exceptions: you may not discuss side payments, make physical threats, or engage in inappropriate language and behavior. You may discuss any aspect of the transaction, and you may make agreements with the sellers. 
However, note that you are in no way bound to the terms of any such arrangements when you actually accept an offer.

At any time, the seller can submit a new offer to you, which you can then accept if you so desire. Hence, you should review the offers carefully to see if they have changed. Sellers must lower their submitted offer. Suppose that Seller 1 lowered his offer to 700. (Seller 1's previous offer was 750.)

The clock in the lower left portion of your screen indicates how much time is remaining in Phase 2 of the period. If you do not accept an offer within the allotted time, you will not purchase a unit that period and your profit will be zero.

$<$ page 8>

The column labeled 'Market Type' summarizes how the market price was determined that period. In this case, 'Negotiations' determined the market price because you had the opportunity to discuss the transaction with the sellers before accepting one offer.

Let's review the important items:

(1) At any time during Phase 2, you may accept the offer of any one seller.

(2) During Phase 2, you can also discuss a transaction with any seller and a seller can submit a new, lower offer.

(3) Your profit is: Value - Price Paid.

$<$ page 9>

This is the end of the instructions. Your earnings in the experiment will be converted into cash at the rate of <insert exchange rate> computer dollars for $\mathbf{1}$ U.S. dollar. If you wish to review the instructions, you may go back at this time. If you feel you now understand the instructions and are prepared to proceed with the actual experiment, click on the 'Start' button. If you have a question that you feel was not adequately answered by the instructions, please raise your hand and ask the monitor before proceeding. Your earnings may suffer if you proceed into the market without understanding these instructions.

<page 1>

\section{Seller/Auction/Differentiation}

This is an experiment in the economics of market decision making. Various foundations have provided funds for this research. The instructions are simple, and if you follow them carefully and make good decisions, you may earn a considerable amount of money that will be paid to you in CASH at the end of the experiment.

In this experiment we are going to create a market in which you will be a seller of a fictitious good in a sequence of periods.

$<$ page $2>$ 
This is your record sheet for the experiment. You can sell at most one unit each period. Notice that you have a cost of 575 for the first period. During the experiment you will only see your cost for the current and past periods.

If you're able to sell (we'll describe the selling process soon), you will receive the difference between the price you receive (the market price) and your cost.

To sum up: Price Received - Cost $=$ Profit .

$<$ page 3>

Notice that your cash profits depend upon your ability to sell a unit at a price above the cost given on your record sheet. Also note that if you sell a unit at a price equal to its cost, your profit will be zero. You cannot sell a unit below your cost.

Your earnings will be automatically entered into your record sheet at the close of each period. Earnings (profits) are accumulated over several periods, with your total earnings at the end of the experiment being your total profit over all periods. The 'Summary Information' frame at the bottom of the screen displays your total profit.

$<$ page 4>

We will now explain the selling procedures. Your job is to attempt to sell a unit of the good in each period by submitting an offer for it. An 'offer' is your selling price offered to the buyer.

Let's go through a sample period. Given your first period cost of 575 you will submit an offer for this unit. Suppose you wanted to sell the unit for 795 . To do so, click on the drop down box below the words 'Submit Offer' in the upper left portion of your screen and select the buyer to whom you are willing to make the offer. Then you type 795 in the box below that and click on the 'Submit' button.

Upon submitting the offer, you will be asked to confirm the offer by clicking 'Yes' or 'No'.

$<$ page 5>

After all of the offers have been submitted by the sellers, how are the winning seller and market price determined? Good question, but first here is some information on the buyer(s).

In this experiment there are $<$ insert number of sellers $>$ sellers total, each attempting to sell one unit to 1 buyer. A buyer can only purchase one unit each period.

There is also a maximum amount that a buyer is willing to pay to purchase a unit from a seller.

$<$ page 6>

Once all of the offers have been submitted by the sellers, a buyer will choose to purchase from the seller that yields the greatest profit, as long as the profit is greater than zero. A buyer's profit is Value - Price Paid. If all of the offers are greater than the buyer's values, then the buyer will not purchase a unit that period. 
If you submitted the offer that yields the buyer his greatest profit, you will sell a unit and your record sheet will be filled in as shown for period 1 . If you do not sell the unit, the column labeled 'Profit' will have a dash entered into it. The offer that the buyer accepted will be displayed in the column labeled 'Market Price,' so that you will have a record of all contract prices.

In the event that two or more sellers tie for the greatest profit for the buyer, the computer will select a winner at random.

The column labeled 'Market Type' summarizes how the market price was determined that period. In this case, the 'Best Offer’ determined the market price.

$<$ page $7>$

Let's review the important items:

(1) In order to make a profit, your offer must be greater than your cost.

(2) You can change your offer if you have not already confirmed it.

(3) The seller who submits the offer yielding the buyer the highest payoff will be the only person to sell a unit to the buyer.

(4) Your profit is: Price Received - Cost.

<page 8>

This is the end of the instructions. Your earnings in the experiment will be converted into cash at the rate of <insert exchange rate> computer dollars for $\mathbf{1}$ U.S. dollar. If you wish to review the instructions, you may go back at this time. If you feel you now understand the instructions and are prepared to proceed with the actual experiment, click on the 'Start' button. If you have a question that you feel was not adequately answered by the instructions, please raise your hand and ask the monitor before proceeding. Your earnings may suffer if you proceed into the market without understanding these instructions.

\section{Seller/Multilateral Negotiation/Differentiation}

$<$ pages 1-3; same as above $>$ $<$ page 4>

We will now explain the selling procedures. Your job is to attempt to sell a unit of the good in each period by submitting an offer for it. An 'offer' is your selling price offered to the buyer.

Let's go through a sample period. Given your first period cost of 575 you will submit an offer for this unit.

\section{Phase 1:}


Suppose you wanted to sell the unit for 1000. To do so, click on the drop down box below the words 'Submit Offer' in the upper left portion of your screen and select the buyer to whom you are willing to make the offer. For these instructions, choose Buyer 1. Then you type 1000 in the box for your offer and click on the 'Submit' button.

Upon submitting the offer, you will be asked to confirm the offer by clicking 'Yes' or 'No'.

$<$ page 5>

After all of the offers have been submitted by the sellers, the period advances to Phase 2. At any time the buyer can accept one of the offers and then the period ends. If the buyer accepts your offer, then the record sheet will be filled in as shown. If you do not sell the unit, the column labeled 'Profit' will have a dash entered into it. The accepted offer will be displayed in the column labeled 'Market Price' so that you will have a record of the contract prices accepted by a buyer.

$<$ page 6>

\section{Phase 2 (continued):}

Instead of immediately accepting one of the seller's offers, the buyer and the sellers have an opportunity to send messages to each other about a transaction. Messages that you send to the buyer (and vice versa) can only be read by you and the buyer. However, the buyer can also send private messages to the other sellers. In the tab in the upper right portion of the screen, you can type your message in the line and click on the 'Send' button.

The column labeled 'Market Type' summarizes how the market price was determined that period. In this case, 'Negotiations' determined the market price because the buyer had the opportunity to discuss the transaction with the sellers before accepting one offer.

You are free to discuss all aspects of the market, with the following exceptions: you may not discuss side payments, make physical threats, or engage in inappropriate language and behavior. You may discuss any aspect of the transaction, and you may make agreements with the buyer. However, note that you and the buyer are in no way bound to the terms of any such arrangements when you actually send an offer.

If at any time you would like to submit a new offer to the buyer, you can do so, but the buyer need not accept it. Furthermore, your new offer must be less than your previous offer. You cannot increase your submitted offer.

<page 7>

In this experiment there are <insert number of sellers $>$ sellers total, each attempting to sell one unit to 1 buyer. A buyer can only purchase one unit each period.

There is also a maximum amount that a buyer is willing to pay to purchase a unit from a seller.

<page 8>

Once a buyer accepts an offer from a seller, you can no longer exchange messages with the buyer. 
Let's review the important items:

(1) In order to make a profit, your offer must be greater than your cost.

(2) You can change your offer if you have not already confirmed it.

(3) At any time, you can withdraw an offer to 1 buyer and submit one to another buyer.

(4) The buyer can accept at most one offer from a single seller.

(5) Your profit is: Price Received - Cost.

$<$ page 9>

This is the end of the instructions. Your earnings in the experiment will be converted into cash at the rate of <insert exchange rate> computer dollars for $\mathbf{1}$ U.S. dollar. If you wish to review the instructions, you may go back at this time. If you feel you now understand the instructions and are prepared to proceed with the actual experiment, click on the 'Start' button. If you have a question that you feel was not adequately answered by the instructions, please raise your hand and ask the monitor before proceeding. Your earnings may suffer if you proceed into the market without understanding these instructions.

Handout Read Out Loud to All Participants

(After Subjects Finished Reading the Above Instructions)

\section{Other Information}

- There are a total of <insert number of sellers> sellers in your market who can sell to a single buyer.

Throughout the entire experiment, the same <insert number of sellers> sellers will be matched with the same buyer.

- Seller costs are assigned randomly. Each seller has an equally like chance of receiving any cost between $\$ 0$ and $\$ 600$, inclusive. That is, each seller is equally likely to receive $\$ 0, \$ 1$, $\ldots$, \$599, \$600. All sellers will receive their own random draw each period for their own cost.

- Furthermore, the chance of a seller being assigned any particular cost in this range, for example, 345, is not changed if that cost was assigned earlier to one seller or to another. It is therefore possible for one seller to get the same cost for different periods or for two sellers to have the same cost in the same period.

- The seller's profit is the difference between his/her cost and the price received, or Price received - cost $=$ Seller's Profit. 
- <if Differentiation Treatment> The buyer value has a different randomly assigned value for each seller each period. The value for a particular seller has an equally like chance of being between $\$ 300$ and $\$ 900$, inclusive. That is, each value is equally likely to be $\$ 300, \$ 301, \ldots$, \$899, $\$ 900$.

- The buyer's profit is the difference between his/her value and the price paid, or Value - Price paid $=$ Buyer's Profit. 


\section{Economic Science Institute Working Papers}

2008

08-02 Oprea, R., Wilson, B. and Zillante, A. War of Attrition: Evidence from a Laboratory Experiment on Market Exit.

08-01 Oprea, R., Porter, D., Hibbert, C., Hanson, R. and Tila, D. Can Manipulators Mislead Prediction Market Observers? 